\title{
Os vídeos como ferramenta didática para o ensino-aprendizagem da Matemática
}

\section{Financeira}

\author{
Videos as a teaching tool for the teaching-learning of Financial Mathematics \\ Los videos como herramienta didáctica para la enseñanza-aprendizaje de las Matemáticas
}

Financieras

Recebido: 22/02/2021 | Revisado: 25/02/2021 | Aceito: 02/03/2021| Publicado: 02/03/2021

Elias Rafael de Sousa

ORCID ID: https://orcid.org/0000-0001-6207-2729 Centro Universitário Alfredo Nasser, Brasil

E-mail: rafaelsousamat@hotmail.com

Cleyton Hércules Gontijo

ORCID ID: https://orcid.org/0000-0001-6730-8243

Universidade de Brasília, Brasil

E-mail: cleyton@unb.br

\begin{abstract}
Resumo
Este trabalho objetiva apresentar o processo do desenvolvimento de uma aplicação didática em sala de aula, utilizando o vídeo como ferramenta de ensino-aprendizagem. Para o processo metodológico, abordar-se-á o modelo críticodialético, nos termos de Gamboa (2013). Orientados pelos autores: Betetto (2011), Ferreira (1975), Moran (1995), Moreira (2006), Rosado (2016), Vogel (2015), que defendem o uso de material audiovisual como ferramenta educacional, bem como referendados na Teoria da Aprendizagem Significativa, foram criados dois vídeos para auxiliar a aprendizagem de matemática financeira em uma turma do $9^{\circ}$ ano do ensino fundamental, de uma escola da rede pública da cidade de Caiapônia - GO. O estudo teve o objetivo de analisar as potencialidades do uso do vídeo em sala de aula como recurso didático para o ensino de tópicos relacionados à matemática financeira. Com a finalidade de avaliar o processo de ensino-aprendizagem em relação ao conteúdo, os alunos criaram seus próprios vídeos, abordando o tema "Matemática financeira no meu cotidiano", nos quais foram tratadas situações reais que demonstraram a aplicação dos conteúdos vistos em sala de aula. Com a exposição dos vídeos produzidos pelos alunos, as metodologias utilizadas nesta atividade atestaram que o vídeo, usado como ferramenta didática de forma adequada, pode contribuir de forma significativa para o ensino-aprendizagem do escolar.
\end{abstract}

Palavras-chave: Vídeo; Matemática Financeira; Aprendizagem Significativa; Recurso Didático.

\begin{abstract}
This work aims to present the process of developing a didactic application in the classroom. For the application of this experiment, video was used as a teaching-learning tool. For the methodological process we will approach the criticaldialectical model, in the terms of Gamboa (2013). Guided by authors: Betetto (2011), Ferreira (1975), Moran (1995), Moreira (2006), Rosado (2016), Vogel (2015), who advocate the use of audiovisual material as an educational tool. As well as endorsed in the Theory of Meaningful Learning, we created two videos to assist the learning of financial mathematics in a 9th grade class at a public school in the city of Caiapônia - GO with the aim of analyzing the potential of using video in the classroom as a didactic resource for teaching topics related to financial mathematics. In order to evaluate the students' teaching-learning process in relation to the content, the students created their own videos addressing the theme "Financial mathematics in my daily life", in which real situations were discussed that demonstrated the application of the contents seen in class of class. With the exposure of the videos produced by the students, and the methodologies used in this activity, they attested that the video, used as a didactic tool in an appropriate way, can contribute significantly to the teaching-learning of the schoolchildren.
\end{abstract}

Keywords: Video; Financial Mathematics; Meaningful Learning; Didactic Resource.

\section{Resumen}

Este trabajo tiene como objetivo presentar el proceso de desarrollo de una aplicación didáctica en el aula. Para el proceso metodológico nos acercaremos al modelo crítico-dialéctico, en términos de Gamboa (2013). Guiado por autores: Betetto (2011), Ferreira (1975), Moran (1995), Moreira (2006), Rosado (2016), Vogel (2015), quienes abogan por el uso del material audiovisual como herramienta educativa. Además de apoyar la Teoría del Aprendizaje Significativo, creamos dos videos para ayudar al aprendizaje de las matemáticas financieras en una clase de noveno grado en una escuela pública de la ciudad de Caiapônia - GO con el objetivo de analizar el potencial del uso del video en el aula. La clase como recurso didáctico para la enseñanza de temas relacionados con las matemáticas financieras. Con el fin de evaluar el proceso de enseñanza-aprendizaje de los estudiantes en relación a los contenidos, los 
estudiantes crearon sus propios videos abordando el tema "Matemáticas financieras en mi vida diaria", en los que se discutieron situaciones reales que demostraron la aplicación de los contenidos presentados en clase. clase. Con la exposición de los videos producidos por los estudiantes y las metodologías empleadas en esta actividad, dieron fe de que el video, utilizado como herramienta didáctica de manera adecuada, puede contribuir de manera significativa a la enseñanza-aprendizaje de los estudiantes.

Palabras clave: Video; Matemáticas Financieras; Aprendizaje Significativo; Recurso Didáctico.

\section{Introdução}

Os meios de comunicação exercem poder e o fascínio sobre as pessoas, especialmente em crianças e jovens, em função da sua "capacidade de articulação, de superposição e de combinação de linguagens totalmente diferentes — imagens, fala, música e escrita - com uma narrativa fluída, uma lógica pouco delimitada, gêneros, conteúdos e ética pouco precisos, o que lhe permite alto grau de entropia” (Moran, 1994, p. 235). Considerando esse poder e fascínio, os sistemas educacionais poderiam inserir cada vez mais elementos dos meios de comunicação nos processos de ensino. O vídeo, por exemplo, pode ser uma ferramenta para o ensino, pois é um recurso que possui um poder extraordinário de atrair a atenção dos alunos, principalmente se a temática atende aos interesses dos expectadores.

Destaca-se que o acesso aos meios de comunicação tem crescido significativamente no Brasil. A Pesquisa Nacional por Amostra de Domicílios Contínua - PNAD Contínua - investigou, em 2018, o acesso o acesso à Internet e à televisão nos domicílios particulares permanentes e o acesso à Internet e a posse de telefone móvel celular para as pessoas de 10 anos ou mais de idade. O levantamento mostrou que em 96,4\% dos domicílios particulares permanentes do país havia televisão e que, de 2017 para 2018, houve aumento acentuado no número de domicílios com televisão de tela fina. O levantamento mostrou, também, que em 2018, nos domicílios com televisão do país, o acesso a serviço de televisão por assinatura correspondia a 31,8\%. Constatou-se, na pesquisa do PNAD, que em 2018, nos domicílios particulares permanentes, a acesso à internet correspondia a $79,1 \%$.

Considerando a presença dos meios de comunicação na vida da população, especialmente da TV, e os potenciais efeitos positivos que este instrumento pode apresentar no processo de ensino e aprendizagem, apresentamos, aqui, um relato de experiência que descreve as etapas de uma proposta de intervenção a partir do uso do vídeo em uma sala de aula do $9^{\circ}$ ano do ensino fundamental, de uma escola da rede pública da cidade de Caiapônia - Goiás. Durante três aulas, trabalhamos o tema matemática financeira, com foco em Juros Compostos e Tabela Price ${ }^{1}$. Ressaltamos que a Base Nacional Comum Curricular (BNCC) inclui temas relacionados educação financeira e fiscal como temas contemporâneos que devem ser incorporados aos currículos e às propostas pedagógicas das escolas e sistemas de ensino do país (Brasil, 2018). Nessas aulas, os alunos assistiram ao vídeo produzido pelos professores, debateram os questionamentos trazidos para a sala, resolveram exercícios e criaram seus próprios vídeos.

Nesse sentido, o objetivo geral deste trabalho foi demonstrar as potencialidades do uso do vídeo em sala de aula como recurso didático para o ensino de tópicos relacionados à matemática financeira, que é assunto presente no cotidiano daqueles alunos. Partimos da constatação de que as tecnologias digitais de informação e comunicação estão presentes no cotidiano de forma intensa e, diante desse panorama, é essencial que a escola esteja preparada para as influências de uma sociedade da informação cada vez mais complexa, na qual o vídeo faz parte da vida contemporânea. Como aporte teórico, necessário para o processo de aprendizagem, apoiamo-nos na Teoria da Aprendizagem Significativa.

\footnotetext{
${ }^{1}$ Tabela Price consiste em um plano de amortização de uma dívida em prestações periódicas, iguais e sucessivas, onde o valor de cada prestação é composto por duas subparcelas distintas: uma de juros e outra de amortização do capital. (Benvenho, 2010).
} 


\section{O Uso do Vídeo na Sala de Aula}

Para Betetto (2011, p.23), “o vídeo é um sistema de informação ímpar, que ao apresentar expressões, linguagem, som e imagem para o âmbito escolar, favorece o trabalho do professor em sala de aula, auxiliando e intensificando a aprendizagem dos escolares". O autor também afirma que é importante destacar que os sentidos, estimulados com o auxílio de um recurso audiovisual, contribuem, significativamente, para o processo de ensino e aprendizagem. Ferreira (1975) destaca que os sentidos estimulados com a ajuda de recursos audiovisuais contribuem significativamente no processo de aprendizagem. Segundo o autor, a visão é o sentido que apresenta maior possibilidade percentual de aprendizagem, desde que se busque privilegiar a interação do sujeito, possibilitando trabalhar o visual e oral simultaneamente. Vaz e Sousa (2020) apresentam o recurso tecnológico como uma grande contribuição, que possibilita ao aluno uma dinamização nas experimentações matemáticas, colaborando com o entendimento de certas propriedades.

A aplicação didática do vídeo permite promover atividades dinâmicas das mais variadas formas, fundamentais para centrar a atenção dos alunos, pela sua versatilidade e pelo seu valor motivacional. Essa ferramenta possibilita despertar a curiosidade dos estudantes, motivando-os para a pesquisa de novos temas e para o aprofundamento dos conteúdos a serem trabalhados. Os educadores têm um papel fundamental, que é tornar o processo de ensino e aprendizagem mais atrativo, instigante e eficaz por meio de práticas inovadoras que proporcionem mais qualidade na educação, e uma delas é o vídeo (Betetto, 2011). A utilização desse recurso possibilita ao aluno evitar o abstrato, aproximando-o do real, fazendo-o relacionar o conteúdo apresentado com seu cotidiano. Moran (1995) apresenta o vídeo como:

[...] recurso que parte do concreto, do visível, do imediato, próximo, que toca todos os sentidos. Mexe com o corpo, com a pele, nos toca e "tocamos" os outros, estão ao nosso alcance através dos recortes visuais, do close, do som estéreo envolvente. Pelo vídeo sentimos, experiências sensorialmente o outro, o mundo, nós mesmos (Moran, 1995, p.1).

Ademais, Vogel (2015) destaca que as crianças e os jovens estão cada vez mais inclinados a serem influenciados por vídeos veiculados pelas emissoras de televisão. "Essa é uma geração que precisa de sensações, das imagens, precisa estar sintonizada para evoluir e aprofundar conhecimentos" (Vogel, 2015, p. 2). Por isso, segundo esse autor, é preciso incorporar essas novas linguagens na educação escolar, uma vez que "um fato mostrado com imagens sempre terá mais significação do que um fato mostrado somente com palavras" (Vogel, 2015, p. 2).

Vogel $(2015$, p. 3) também afirma que "com o passar do tempo, o vídeo ganhou muita importância no processo de comunicação e interação. É uma forma que se tem para não deixar as aulas caírem na rotina, tornarem-se monótonas e cansativas". Na alvorada do YouTube², a utilização de vídeos durante a aula já não é recebida pelos estudantes com a mesma expectativa daquela que ocorria nas décadas passadas. A profusão de opções à disposição dos alunos exige um aprimorado senso crítico do docente, que deve observar, além da qualidade das imagens, se o vídeo selecionado oferece apenas um entretenimento ou é mesmo relevante para a aprendizagem.

Segundo Moran (1995), a falta de um professor na sala de aula pode fazer com que os estudantes sejam levados para a sala de vídeo, o que não é ruim, mas poderia ser mais bem aproveitado. Esta é uma situação comum na rede pública de ensino. Em parte, isso se explica pela disposição dos alunos que, mesmo acostumados com os vídeos, veem o momento do filme como algo diferente na rotina escolar e, com frequência, dedicam até mais atenção ao que se passa na tela do que às aulas comuns. No entanto, uma atividade que podia ser aproveitada para trabalhar habilidades importantes, acaba sendo desperdiçada quando a prioridade é apenas manter a turma sob controle (Moran, 1995).

\footnotetext{
${ }^{2}$ YouTube é um site que permite o compartilhamento de vídeos.
} 
Esse mesmo autor afirma que o vídeo é um eficiente suporte à aprendizagem, ainda que os estudantes já o tenham assistido em outro momento, pois "o contexto escolar favorece a expectativa de um debate ou a tarefa de produzir uma resenha”. Segundo Ferres (1996), há assuntos em que o método audiovisual possibilita a ativação de sentidos que as elucidações orais tradicionais não proporcionam.

Embora o vídeo seja uma ferramenta importante para a educação, ele ainda é usado de forma inadequada. Isso ocorre quando, por exemplo, o vídeo é utilizado para resolver algum contratempo ou ainda quando o profissional recorre a esse recurso sem nenhuma articulação com seus objetivos da sala de aula. E é nesse sentido que, no quadro a seguir, Moran (1995) descreve, diferentes usos inadequados do vídeo em sala de aula.

Quadro 1 - Principais situações do uso inadequado do vídeo em aula

\begin{tabular}{|c|l|}
\hline Vídeo tapa-buraco & $\begin{array}{l}\text { Quando se coloca um vídeo para cobrir a ausência de um professor. O aluno } \\
\text { associa o vídeo a não ter aula. }\end{array}$ \\
\hline Vídeo enrolação & $\begin{array}{l}\text { Um vídeo sem ligação com o conteúdo. Com isso o aluno consegue percebe } \\
\text { que o vídeo é usado para embair a aula. }\end{array}$ \\
\hline Só vídeo & $\begin{array}{l}\text { Quando o professor exibe o vídeo em sala de aula, mas não estimula o debate } \\
\text { ou alguma outra atividade. }\end{array}$ \\
\hline
\end{tabular}

Fonte: Moran (1995).

Diante de tais informações, percebe-se que o potencial educativo desse material depende da maneira como ele é utilizado. Devem-se ser considerados como aspectos essenciais um planejamento bem elaborado e os objetivos préestabelecidos pelos docentes. Outrossim, o uso da tecnologia na educação, na qual o professor é o detentor do conhecimento e o aluno um simples receptor passivo, certamente não contribuirá para que se logrem bons resultados.

O professor pode utilizar o vídeo para tornar sua aula mais atrativa, além de despertar em seus alunos a sensibilidade, a emoção e a criatividade, o que favorece a aprendizagem. Para isso, Moran (1995) apresenta uma proposta adequada para o uso do vídeo que pode ser adotada para introduzir um novo conteúdo escolar, de modo a motivar e provocar a imaginação dos alunos e, ainda, ele pode ser usado para ajudar o professor a avaliar o desenvolvimento de seu próprio trabalho.

Quadro 2 - Descrição do uso adequado do vídeo em sala de aula

\begin{tabular}{|c|l|}
\hline Vídeo com sensibilização & $\begin{array}{l}\text { O vídeo pode ser usado para introduzir um novo assunto, despertar a } \\
\text { curiosidade e a motivação para novos temas. }\end{array}$ \\
\hline Vídeo com ilustração & $\begin{array}{l}\text { O vídeo ajuda a mostrar o que se fala em aula e a compor cenários } \\
\text { desconhecidos pelos alunos. }\end{array}$ \\
\hline Vídeo como simulação & $\begin{array}{l}\text { O vídeo pode simular experiências que seriam perigosas em laboratórios ou } \\
\text { que exigiriam muito tempo e recurso. }\end{array}$ \\
\hline $\begin{array}{c}\text { Vídeo como conteúdo de } \\
\text { ensino }\end{array}$ & Vídeo que mostra de forma direta assunto estipulados. \\
\hline Vídeo como produção & $\begin{array}{l}\text { Vídeo produzido por alunos ou professores que registra aulas, experiências, } \\
\text { entrevistas ou depoimentos. }\end{array}$ \\
\hline
\end{tabular}

Fonte: Moran (1995).

Moran (1995) ainda propõe algumas formas para analisar o vídeo em classe, nas quais o docente deve provocar nos estudantes a reflexão, o que pode resultar numa relação com o conteúdo trabalhado ou com a realidade do cotidiano deles, apresentando diferentes linguagens e características culturais. 
Quadro 3 - Descrição dos métodos para análise do vídeo em classe

\begin{tabular}{|c|c|}
\hline Análise em conjunto & $\begin{array}{c}\text { O professor exibe o vídeo e comenta junto aos alunos. Ele não apresenta primeiro a } \\
\text { dar sua opinião, deve-se posicionar-se depois dos alunos, comparando, se } \\
\text { necessário, o ideal com o real. }\end{array}$ \\
\hline Análise concentrada & $\begin{array}{c}\text { O professor escolhe, depois da exibição, uma ou duas cenas marcantes e cria } \\
\text { questões específicas referentes a este trecho. }\end{array}$ \\
\hline Análise funcional & $\begin{array}{l}\text { Antes da exibição, o professor passa algumas atividades para serem feitas durante o } \\
\text { vídeo como, por exemplo, anotar as palavras-chave. }\end{array}$ \\
\hline Análise da linguagem & $\begin{array}{c}\text { O professor pode propor uma análise da linguagem, da ideologia e dos valores } \\
\text { abordados no vídeo. }\end{array}$ \\
\hline
\end{tabular}

Fonte: Moran (1995, p.32).

Podem existir vários outros métodos de análise de recursos audiovisuais. Ainda existem muitos desafios a serem superados para a inserção significativa dessa ferramenta no cotidiano escolar, a fim de se possibilitar as suas contribuições e benesses no que diz respeito ao aprendizado dos alunos.

\section{Alguns Aspectos da Teoria da Aprendizagem Significativa}

A teoria da aprendizagem significativa foi formulada inicialmente pelo psicólogo norte-americano David Paul Ausubel. Suas ideias, cujas concepções iniciais são da década 1960, estão entre as primeiras propostas psicoeducativas sobre fatores cognitivos, afetivos e sociais da aprendizagem. Segundo Moreira (2006), o intuito central da aprendizagem significativa é uma reorganização cognitiva estrutural, ou seja, faz parte de uma evolução de novas informações por meio das quais são estabelecidos conceitos significativos na estrutura do conhecimento dos escolares. Esses conhecimentos têm como função as concatenações mentais, transformando o entendimento dos escolares em aprendizagem.

A aprendizagem significativa busca designar associações entre os novos conhecimentos e os conceitos prévios dos alunos. Em contrapartida à aprendizagem significativa, existe a aprendizagem mecânica, que, para Ausubel, é a aprendizagem que, dessemelhante do processo significativo, decorre quando o estudante, recém-apresentado a uma recente informação, não a relaciona com os conceitos prévios incorporando a sua estrutura cognitiva (Moreira, 2006).

A estes conceitos pré-existentes Ausubel dá o nome de subsunçor, o que pode ser entendido como uma proposição ou uma ideia preexistente na estrutura cognitiva do aprendiz que serve de base de ligação a uma nova informação, permitindo ao indivíduo atribuir-lhe significado. Conforme Moreira (2006), Ausubel estabelece algumas condições para que ocorra uma aprendizagem significativa:

- Devem existir previamente conceitos subsunçores na estrutura cognitiva, capazes de servir de ancoradouro a uma nova informação, de modo que esta adquira significado para o estudante.

- O estudante precisa ter disposição para aprender.

- O conteúdo escolar, juntamente como material didático desenvolvido, deve ser, sobretudo, significativo para o aluno.

Quando não existem subsunçores, Ausubel recomenda, como estratégia para manipular a estrutura cognitiva, o uso de organizadores prévios que sirvam de amparo para a nova aprendizagem e levem ao desenvolvimento de conceitos subsunçores, que facilitem a aprendizagem subsequente. Tais organizadores prévios seriam materiais introdutórios apresentados antes do próprio material a ser aprendido e teriam a função de servir de "pontes cognitivas" entre o que o aprendiz já sabe e o que ele deve saber, buscando-se garantir que a aprendizagem seja significativa (Moreira, 2006). 
Santos (2007), ao abordar a Teoria da Aprendizagem Significativa, afirma que uma aula significativa é aquela que contribua para que o aluno construa significados. E ela pode ser dividida em três partes: construção do sentido, apresentação do conteúdo e verificação da aprendizagem. Na fase inicial de uma aula significativa, devem-se inserir contextos da realidade da vida do aluno, começando a aula com situações contextuais inclusivas. Essas situações, presentes no cotidiano dos estudantes, podem ser estruturadas como organizadores prévios que possibilitarão a criação de subsunçores, ou seja, ideias e conceitos iniciais que facilitarão o aprendizado nas próximas etapas.

Na segunda parte da aula, deve-se construir o significado junto ao aluno, ou seja, nada de conceitos prontos. Em uma aula significativa, o professor deve fazer com que os próprios alunos descubram o tema da aula e participem do processo de descoberta de significados que sejam relevantes para sua vida. Por fim, devem-se propor desafios com valores socioculturais para comprovar o desenvolvimento de competências. Uma longa lista de exercícios apenas irá exigir que o aluno repita passos ou aplique fórmulas para encontrar respostas. Ao contrário, quando o aluno consegue relacionar o conteúdo visto em sala com situações reais do seu cotidiano, elaborar problemas e desenvolver soluções, entende-se que a aprendizagem foi significativa e ele apropriou-se do conhecimento. Os métodos que utilizamos para trabalhar as três condições para a aprendizagem significativa, juntamente com as três partes necessárias para uma aula significativa, estão detalhados nos próximos tópicos deste relato de experiência.

\section{Metodologia}

A pesquisa se balizou na abordagem qualitativa, de acordo com Chizzotti (2003). Para esse autor, uma pesquisa qualitativa:

[...] tende para o estudo de questões delimitadas, locais, apreendendo os sujeitos no ambiente natural em que vivem nas suas interações interpessoais e sociais, nas quais tecem os significados e constroem a realidade. Assim, a abordagem permite análises contextualizadas dos fenômenos da realidade social, do conhecimento e do ser humano em sua totalidade. (Chizzotti, 2003, p. 229-230).

O método abordado tem o enfoque crítico-dialético, que tem como seu principal núcleo compreender o fenômeno em seu caminho histórico e em suas inter-relações com outros fatos. Tal método tem como objetivo compreender o caminho de transformação, suas contestações e suas potencialidades. Para Sousa (2017), para tal enfoque, o homem conhece para transformar e o conhecimento tem fundamentação quando apresenta as alienações, as opressões e as misérias do atual ponto de desenvolvimento. "O conhecimento crítico do mundo e da sociedade e a compreensão de sua dinâmica transformadora propiciam ações (práxis) emancipadoras” (Gamboa, 2013, p. 75).

\subsection{Descrição da Proposta de Intervenção em sala de aula}

Inicialmente, para se entender as etapas que desenvolvemos para construir este trabalho, é necessário compreender a proposta que elaboramos para fazer uma intervenção em sala de aula, utilizando o vídeo como recurso didático. Portanto, discorremos, logo em seguida, sobre o processo que mediou todo o nosso trabalho durante a aplicação da proposta.

\subsection{Escolha do tema}

O tema a ser trabalhado em sala foi a matemática financeira, com o eixo em Juros Compostos e Tabela Price, visto que este é um tema presente na vida dos alunos e vigente nos currículos da disciplina. O endividamento da população é um tema preocupante que afeta o Brasil, assim como qualquer outro país. Em 2011, o então ministro da justiça, Luiz Paulo Barreto, disse, em entrevista ao Jornal Estadão, que era necessário educar a população de modo que os consumidores 
soubessem claramente o quanto pagam por um determinado produto comprado a prazo e qual é a fatia da taxa de juros. Disse também que era "preciso enfatizar a esse consumidor a possibilidade de se fazer poupança para adquirir um bem, no futuro, com pagamento à vista e solicitar desconto" (Estadão, 2011). Concordantes com estes dizeres, também destacamos a importância do conhecimento em matemática financeira para a resolução de problemas do cotidiano. O conteúdo precisa ser ensinado nas escolas e tal ideia é apoiada pelos professores de matemática; entretanto, são poucos os que abordam o assunto em sua prática cotidiana.

Segundo a BNCC, é importante que o ensino fundamental proponha aos escolares o desenvolvimento e o letramento matemático. Esse documento define como competências: “(...) habilidades de raciocinar, representar, comunicar e argumentar matematicamente, de modo a favorecer o estabelecimento de conjecturas, a formulação e a resolução de problemas em uma variedade de contextos, utilizando conceitos, procedimentos, fatos e ferramentas matemáticas” (Brasil, 2018, p. 266).

Destaca-se também, entre as expectativas de aprendizagem dos anos finais do ensino fundamental, a capacidade de que "os alunos devem dominar o cálculo de porcentagem, porcentagem de porcentagem, juros, descontos e acréscimos, incluindo o uso de tecnologias digitais" (Brasil, 2018, p. 269). Tais situações já devem existir no dia a dia destes alunos, mesmo com pouca idade. Empréstimos entre amigos e familiares, compras feitas sob sistemas de amortização e vendas em pagamentos parcelados são situações que podem estar presentes na realidade de qualquer adolescente.

Portanto, ensinar matemática financeira, mesmo que apenas uma parte dela, é preparar os alunos para a vida em sociedade, uma vez que possui evidente caráter prático, o que vai ao encontro das propostas da Teoria da Aprendizagem Significativa. Ademais, para além da sala de aula, o ensino da matemática financeira acerca de problemas reais pode contribuir para a formação de um indivíduo crítico e atuante.

\subsection{Adaptação da Teoria da Aprendizagem Significativa}

Ao adotar a Teoria da Aprendizagem Significativa como aporte teórico para o desenvolvimento deste trabalho, nos preocupamos em atender as três condições necessárias para que ocorra uma aprendizagem significativa: devem existir conceitos subsunçores na estrutura cognitiva do aluno; o estudante precisa estar disposto a aprender; e o conteúdo escolar, juntamente com o recurso didático, deve ser significativo para o aluno. Como não é possível investigar a estrutura cognitiva de cada aluno, tampouco construir um material educacional individualizado, preparamos um material para ser trabalhado em sala de aula antes do conteúdo principal. Esse material teve a função de atuar como organizadores prévios, a fim de garantir que os subsunçores necessários à aprendizagem estivessem presentes na estrutura cognitiva dos alunos. Tais organizadores prévios garantiram a existência de subsunçores necessários às próximas etapas da aprendizagem.

Para atender à segunda condição, na qual o aluno precisa ter disposição para aprender, utilizamos o vídeo em sala de aula por entender que ele promove uma aula significativa ao motivar, emocionar ou simplesmente chamar a atenção dos estudantes. É preciso motivação para aprender e, para isso, a atenção é fundamental.

Por fim, o vídeo, utilizado como recurso didático, pode trazer cenas do cotidiano dos estudantes e situações práticas que aproximam o conteúdo escolar da realidade do indivíduo, bem como favorecer a ligação do novo com o que já é conhecido. Tudo isso, somado ao aprendizado de matemática financeira, que é assunto presente no dia a dia dos alunos, contribui para atender à terceira condição necessária à aprendizagem significativa.

\subsection{Elaboração do vídeo}

Alguns motivos nos levaram a optar pela criação de um vídeo para a aplicação desta proposta: 
- não encontramos vídeos que abordassem somente os tópicos relacionados à matemática financeira que iríamos trabalhar em sala;

- não encontramos vídeos que trouxessem exemplos de aplicação da matemática financeira próximos à realidade dos alunos da escola em questão;

- não encontramos vídeos com linguagem apropriada para a faixa etária da turma.

Portanto, a partir dos dados coletados durante o diagnóstico do conhecimento da turma no que tange ao conteúdo a ser ministrado, bem como as suas peculiaridades, foi inicialmente concebido um roteiro que atendesse às características desta turma propriamente dita. De posse deste roteiro, foram concebidos os vídeos que subsidiaram o nosso trabalho. É importante registrar, aqui, a mobilização de várias pessoas para a concretização deste material, que julgamos ser útil para todos os profissionais que trabalham nesta área de ensino. Constatamos que, praticamente, não existem materiais audiovisuais dessa natureza disponíveis para subsidiar o trabalho do professor. Nesse sentido, temos que esse material não se restringiu apenas em auxiliar a aplicação desta proposta, mas constituiu-se em importante legado não só para a professora que nos acompanhou durante as aulas, mas para todos os profissionais de Matemática que tanto se queixam da falta de materiais. Entretanto, entendemos que, embora esta seja uma tecnologia de fácil acesso, os professores ainda apresentam dificuldades para incorporar o vídeo como um recurso educacional em sua prática.

A opção de criar um vídeo para exibir em sala não significa que todo professor deve criar seus próprios vídeos. Existem vários vídeos disponíveis na internet, de variados assuntos e com indicações para muitos casos. O professor deve buscar vídeos prontos que se adequam a sua proposta antes de se dar o trabalho de criar um vídeo. Para a elaboração do vídeo, escolhemos o software PowToon, por ser de fácil manuseio. Para a produção das trilhas musicais e vozes apresentadas no vídeo, foi utilizado o software Pro Tools, este mesmo software é utilizado em gravações de áudio para dublagem de filmes e programas de TV. Além dos programas de computador, contamos com a participação de quatro atores para a dublagem dos personagens dos dois vídeos, sendo eles duas mulheres (uma adulta e uma criança) e dois homens (um adulto e uma criança).

Os vídeos, utilizados nesta proposta, foram cuidadosamente elaborados para ser um material didático significativo para o aluno. Eles foram desenvolvidos com uma linguagem própria para a faixa etária daquela turma, criados em formato de animação 2D, com dublagem realizada por crianças e uma linguagem coloquial característica da nossa região. Também foram despendidos esforços para que este material possuísse boa qualidade de imagem, em alta resolução, e de som, sendo que seu áudio foi gravado em estúdio próprio para este fim. Todos estes detalhes foram trabalhados segundo as orientações de Moran (1995), o qual diz que a qualidade do audiovisual e o cuidado com a idade dos alunos são elementos essenciais para que se tenha um bom resultado. Além disso, um material didático significativo para o aluno é uma das condições necessárias para uma aprendizagem significativa, segundo Ausubel (Moreira, 2006).

Ainda seguindo as orientações de Moran (1995), os vídeos foram construídos segundo as características de um vídeosensibilização, o qual é indicado para introduzir um novo assunto, despertar curiosidade e motivar os alunos. Também nos apoiamos no método da Análise em conjunto, indicado pelo mesmo autor, para promover o debate em sala de aula. Para isso, foram inseridos no filme questionamentos direcionados à sala de aula. Nesses momentos, o vídeo era pausado e os professores refaziam a pergunta instigando os alunos a responder, comentar e exemplificar situações semelhantes presentes no seu cotidiano. Isso fez com que acontecesse a troca de ideias entre estudantes, o que, naquele momento, foi interessante para envolver e motivar toda a turma, até os alunos tidos como os mais "quietos". 


\section{Resultados e Discussão}

\subsection{Apresentação da proposta}

Dividimos a proposta em três partes. Na primeira delas, buscamos responder à pergunta: o que foi feito para a aplicação do experimento? Durante as três aulas destinadas à aplicação do experimento, trabalhamos o conteúdo de Matemática financeira, com eixo central em juros simples, juros compostos e Tabela Price (sistema de amortização praticado pelo comércio), de acordo com as condições exigidas pelo Documento Curricular do Estado de Goiás para o segundo bimestre, do $9^{\circ}$ ano do Ensino Fundamental de uma escola da rede pública da cidade de Caiapônia - GO.

$\mathrm{Na}$ segunda parte, visamos responder ao questionamento: como foi feita a aplicação do experimento? Para tanto, criamos dois vídeos e panfletos que tornam possíveis trabalhar os assuntos citados de sala de aula de modo que tais situações sejam adjacentes à realidade desses alunatos. Tais situações ilustram as aplicações de cálculos de porcentagem e juros em contextos comerciais.

Finalizando, nos ocupamos em identificar: como foi verificada a aprendizagem do aluno? Desse modo, Solicitamos aos alunos a criação de seus próprios vídeos, com o tema: "A Matemática financeira no meu cotidiano", nos quais o conteúdo abordou situações vivenciadas pelos alunos, relacionando os conteúdos vistos em sala de aula. A correção das listas de exercícios, juntamente com a análise da produção dos vídeos criados por eles, certificou o desenvolvimento e a evolução da aprendizagem sobre o conteúdo.

\subsection{Sobre as aulas}

A nossa proposta foi desenvolvida em três aulas de 50 (cinquenta) minutos cada, e elas aconteceram durante as aulas da professora de Matemática da instituição de ensino. A professora, além de já ter, em momento anterior, contribuído com a aplicação de nosso diagnóstico da turma, esteve também presente durante o desenvolvimento da proposta, o que foi de fundamental importância para troca de experiências. É interessante ressaltar, aqui, o quanto a professora em questão foi motivada quanto à utilização do recurso vídeo, alegando, em alguns momentos, em troca de experiências, sobre o quanto ficou satisfeita com a participação e com o interesse de seus alunos durante as aulas. Afirmou também que nunca havia utilizado vídeo em suas aulas, justificando que apresentava dificuldade em lidar com este recurso.

\subsection{Sobre a turma de alunos}

As aulas desta proposta aconteceram em uma turma do $9^{\circ}$ ano do Colégio Estadual da cidade de Caiapônia - Go. Trata-se de uma turma do período matutino, com 25 alunos, dentre os quais 10 são meninos e 15 meninas. A idade destes alunos varia entre 13 e 15 anos, e, segundo a professora de Matemática, esta é uma turma que apresenta um rendimento satisfatório na disciplina. Anteriormente à aplicação da proposta, foi realizado um diagnóstico da turma no que tange ao conhecimento que já possuíam sobre o conteúdo que seria ministrado, o que foi importante para a construção dos vídeos a serem trabalhados. A turma em questão, em sua maioria, demonstrou já possuir conhecimento razoável sobre o conteúdo porcentagem, o que para nós foi importante, já que esta constatação nos direcionou quanto à construção dos vídeos que protagonizaram a nossa proposta. Os detalhes da intervenção em sala de aula para aplicação desta proposta estão agrupados de acordo com cada um dos encontros. A seguir, descrevemos as etapas da sequência didática.

Iniciamos o primeiro encontro expondo, por meio de um projetor de vídeo, alguns panfletos, que simulavam promoções de alguns itens que poderiam ser de interesse dos alunos. Entre os panfletos também havia propagandas de agências financeiras que realizavam empréstimos para adolescentes. 
Figura 1 - Panfleto utilizado durante a aula.

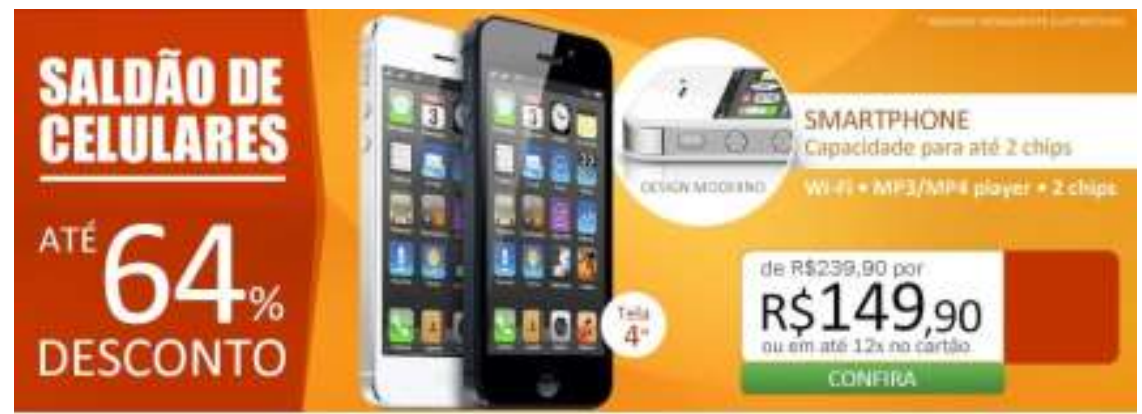

Fonte: próprios autores.

O primeiro panfleto, apresentado na Figura 1, trazia uma situação que exigia dos alunos o trabalho com taxas percentuais para encontrar valores de descontos de acordo com a condição de pagamento. O objetivo principal, nesse momento, era conhecer o que os alunos já sabiam sobre o cálculo de porcentagens. Felizmente, todos os alunos demonstraram saber efetuar estas contas, pois, segundo eles, a professora de matemática havia revisado este conteúdo em suas últimas aulas, como havia sido solicitado por nós.

Outras imagens, também criadas pelos autores desta proposta, foram expostas para verificar se a palavra juros e o seu conceito já estavam presentes no vocabulário dos estudantes. Os panfletos traziam situações de acréscimos de valores para vendas com pagamento parcelado e, também, aumento da dívida contraída em um empréstimo por determinado período.

É importante salientar que, em nenhum momento, as palavras porcentagem e juros foram mencionados. A exposição das imagens e as perguntas direcionadas à classe foram trabalhadas como organizadores prévios e fizeram com que os próprios alunos falassem estas palavras e explicassem, a seu modo, qual era o significado de cada uma delas.

Esta primeira atividade nos levou a confirmar que já existiam, na mente dos alunos, subsunçores necessários para dar sequência às próximas etapas e, além disso, que tais assuntos, relacionados à matemática financeira, estavam presentes no cotidiano daquela turma. A próxima etapa, ainda realizada no primeiro encontro, foi a exposição de um vídeo ${ }^{3}$ que simulava uma situação de empréstimo financeiro envolvendo juros compostos. Esta obra, elaborada pelos autores deste trabalho, apresenta a história de uma menina que, para comprar um aparelho de telefone celular novo, pede dinheiro emprestado para a sua mãe. Foram inseridos no filme questionamentos direcionados à sala de aula. Nesse momento, o vídeo era pausado e o professor mediador refazia as perguntas instigando os alunos a responder, comentar e exemplificar situações semelhantes presentes no seu cotidiano. Isso fez com que acontecesse a troca de ideias entre estudantes, o que foi interessante para envolver e motivar toda a turma, até os alunos tidos como os mais "quietos".

Após esta primeira exibição, o professor fez questionamentos sobre as palavras-chave e alguns conceitos apresentados durante o vídeo, já que foi solicitado aos alunos que anotassem em seus cadernos as palavras que eram destacadas durante a narração, sendo que as palavras porcentagem e juros foram basicamente comuns a todos e, portanto, representavam o fato de que o trabalho com o vídeo caminhava para atingir ao objetivo proposto, já que a ideia, naquele momento, era fazer com que o aluno chegasse a um aprendizado que lhe fosse significativo, e, desse modo, não dado.

Na sequência, foram refeitos os cálculos de juros abordados no vídeo. Também foram criados outros exemplos acerca de juros simples e compostos, além de se solicitar a alguns alunos os resolvessem no quadro negro, incentivando novamente a participação dos alunos durante a aula. Esse foi um momento em que percebemos certo envolvimento da turma, salvo uma parcela, que demonstrava alguma dificuldade na resolução dos problemas apresentados. Inicialmente, houve certo

\footnotetext{
${ }^{3}$ Link para acesso ao vídeo 1 : https://www.youtube.com/watch?v=wbq6mz1Y_dg
} 
acanhamento por parte de alguns alunos quanto ao envolvimento com as propostas. Entretanto, o que se percebeu foi que, paulatinamente, esses alunos participavam mais. Interessante destacar que a exposição do conteúdo, amparada pelo vídeo que naquela hora era apresentado como plano de fundo, suscitava um interesse maior por parte dos alunos, e, consequentemente, maior participação nas atividades.

O segundo encontro iniciou-se com um breve comentário sobre algumas práticas financeiras existentes no comércio. Aos alunos, que agora possuíam subsunçores necessários para o aprendizado de sistemas de amortização, foi explicado que os exemplos trabalhados com juros simples e juros compostos eram restritos às transações financeiras. A matemática financeira utilizada no comércio era mais complexa, com novas características, sendo a principal, o pagamento de parcelas.

Quando os estudantes relataram situações que envolviam o pagamento de parcelas em compras que eles, ou seus pais, já realizaram, o professor apresentou que no comércio o sistema de amortização de dívidas mais utilizado é a chamada Tabela Price, criada em 1777 por Richard Price, que tem por característica principal o pagamento de parcelas iguais.

Após essa introdução, iniciou-se a exposição do segundo vídeo ${ }^{4}$, também elaborado pelo autor /professor sob as mesmas orientações teóricas de Moran e Ausubel. O segundo vídeo, assim como o primeiro, apresenta uma situação em que uma mulher procura, na Internet, uma TV em promoção. Então, diante da oferta de um site de vendas, ela fica na dúvida se é válido comprar a TV à vista ou a prazo. Aplicando a Tabela Price, ela toma conhecimento de quanto pagará, de fato, pelo aparelho. Embora haja fórmulas prontas para facilitar o cálculo, o interessante da Tabela Price é saber exatamente o valor total da compra e quanto se pagou de juros para a loja. Por esta tabela, é possível saber, por exemplo, se há ou não juros já embutidos no valor à vista do produto.

Assim como no primeiro vídeo, trabalhando em aula anterior, a cada questão trazida pelo material audiovisual eram feitas novas pausas, momentos que fomentavam o debate e a troca de experiências entre os alunos. Dentre estas questões, constavam: "Qual opção é a melhor: à vista ou a prazo?"; "Por que, mesmo tendo quitado a dívida, ainda restaram valores a pagar?”; "Será que o valor da TV à vista está correto?”; “Quanto irei pagar de juros nesta compra?"

Foi possível observar que a atividade financeira já fazia parte do dia a dia daqueles indivíduos que, mesmo com pouca idade, já citavam vários exemplos de aquisições e endividamentos, como, por exemplo, a aluna Vitória, de 14 anos, que discorreu sobre o valor final exorbitante do aparelho celular que sua mãe lhe comprara de presente em uma loja. Laura, de 15 anos, afirmou já ter comprado a prazo pela internet, utilizando para tal o cartão de crédito do pai. Alguns afirmaram pedir descontos quando vão comprar algum produto. Esses exemplos confirmam a necessidade de se trabalhar a matemática financeira, com foco no contexto do comércio. Nesta aula, a utilização da Tabela Price evidenciou, para os alunos, o processo envolvido na resolução de problemas com juros compostos no contexto do mercado. Entendemos que o trabalho realizado em sala, utilizando esse método, contribuiu com a autonomia do aluno.

A exposição do segundo vídeo foi concluída com a explicação dos cálculos contidos no filme e a resolução de novos exemplos no quadro negro. Nesse momento, foi entregue aos alunos uma pequena lista de exercícios sobre juros compostos, alguns foram retirados de livros didáticos e outros adaptados e reelaborados por nós, aplicadores da proposta. Foi apresentada, também, a proposta final a ser desenvolvida para o último encontro, em que os alunos foram desafiados a criar seus próprios vídeos, abordando o tema "Matemática financeira no meu cotidiano". Os alunos foram orientados a abordarem situações reais que demonstrassem a aplicação dos conteúdos vistos em sala de aula.

É importante ressaltar que o professor não apresentou fórmulas prontas para a resolução dos exercícios propostos. A metodologia aplicada, para encontrar respostas aos problemas apresentados, foi a de construção de tabelas para compreender a evolução dos valores dos juros em cada período, o que, além de facilitar o entendimento do porquê da resposta final, também

\footnotetext{
${ }^{4}$ Link para acesso ao vídeo 2: https://www.youtube.com/watch?v=UDjxdKfgtU4
} 
evidencia o crescimento de uma dívida ao longo de um período e a importância de se ter uma consciência financeira para evitar grandes endividamentos.

Os alunos foram desafiados a criarem seus próprios vídeos com o tema "matemática financeira no meu cotidiano". O vídeo deveria conter o conteúdo trabalhado em sala de aula, abordado em situações do seu dia a dia, ou seja, deveria conter um valor sociocultural para que a aprendizagem ocorresse de forma significativa (Moreira, 2006). Para a realização dessa atividade, a turma foi dividida em grupos de 04 (quatro) alunos, e foi entregue uma lista contendo algumas dicas para a criação do que Moran (1995) chama de vídeo-produção.

O último encontro foi reservado para a etapa final de uma aula significativa: a verificação da aprendizagem. Nessa aula, os alunos trouxeram as respostas da lista de exercícios entregue anteriormente para correção em sala de aula. A lista de exercícios, que foi elaborada pelo autor desta proposta, continha cinco exercícios que questionavam sobre o valor do montante resultante de um determinado empréstimo, o valor total de juros cobrados em um pagamento parcelado e qual opção de compra parcelada era a mais vantajosa, entre outras. Todos os alunos entregaram a lista de exercícios resolvida e com as respostas esperadas. Observamos que a metodologia empregada na resolução das questões foi a de se trabalhar com tabelas para visualizar a evolução dos juros, assim como foi apresentado nos vídeos e explicado em sala de aula.

A terceira aula também foi o momento de receber o vídeo-produção de cada grupo. Foram apresentados seis vídeos criados pelos grupos de alunos. Todos eles foram filmados com um aparelho de telefone celular e, em quatro casos, foram utilizados recursos de edição de vídeo. Os vídeos foram apresentados em sala de aula para que todos os integrantes dos demais grupos pudessem opinar, sugerir correções e debater as situações filmadas por eles.

Os materiais apresentados continham situações que envolviam empréstimos entre amigos, compras em lojas virtuais e simulações de compras no comércio local, todas elas apresentadas em formato de teatro filmado, sendo os alunos os próprios personagens. Em cada vídeo foram apresentados os cálculos matemáticos referentes às situações elaboradas pelos alunos, como foi solicitado na lista de dicas para criação do vídeo, entregue no final da segunda aula.

Como na lista de exercícios, os alunos utilizaram a metodologia de cálculos por tabelas para encontrar o montante de algum empréstimo e explicar os valores de juros cobrados em uma compra parcelada. Pode-se observar, por meio dos vídeos, que os estudantes dominaram a técnica de cálculos de juros por tabelas, pois em todos os vídeos eles demonstravam de forma correta a evolução dos juros em um determinado caso e, além de encontrar respostas corretas para cada situação, demonstraram saber decidir se uma compra parcelada é ou não vantajosa.

\section{Conclusões}

O vídeo é uma ferramenta potencializadora em sala de aula quando usado corretamente. É de grande importância que o mediador planeje com antecedência a atividade para evitar o fato de que o filme seja apenas um momento de descontração, não construindo um caminho de aprendizado para o aluno. Com isso, é necessário que o professor mediador conheça seus alunos ao ponto de reconhecer a atividade mais sensata a ser aplicada para cada grupo. Concluímos, também, que essa atividade alterou a rotina das aulas; com isso, os alunos apresentaram um maior interesse relacionado às aulas expositivas.

Com a conclusão da terceira aula, ao apresentar a proposta de intervenção utilizando o vídeo com ferramenta para o recurso didático, observamos que, no decorrer da apresentação dos vídeos produzidos pelos alunos, eles conseguiram relacionar a matemática financeira em seu cotidiano, demonstrando conhecimentos essenciais em situações de compra, empréstimo, vendas e financiamentos em contextos comerciais, conforme ordenado no currículo escolar. Além disso, eles apresentaram uma melhor decisão sobre as possibilidades de pagamento e sobre a importância do conhecimento relativo ao percentual de juros aplicado nas práticas financeiras. 
Em suma, a análise da lista de exercícios e dos vídeos mostrou o desenvolvimento de cada aluno, o que evidencia uma aprendizagem significativa. Ressaltamos que a utilização do vídeo como recurso didático e as atividades colaboraram para uma aprendizagem significativa, favorecendo a emancipação dos conhecimentos adquiridos pelos alunos. Se a proposta dos educadores é tornar o processo de ensino-aprendizagem mais atrativo, o vídeo com ferramenta empregada adequadamente, em sala de aula, certamente é um recurso iminentemente significativo, promovendo, assim, uma educação de qualidade.

Após a experiência de uso do vídeo como uma ferramenta potencializadora em sala de aula, acreditamos que tal proposta pode ser de grande valia para trabalhos futuros. Ele pode ser empregado para trabalhar diversos conteúdos matemáticos, entre eles, destacamos: a estatística com a análise de dados e gráficos, o sistema de numeração egípcia e assuntos abordando a história matemática, entre outros.

\section{Referências}

Betetto, J. R. (2011). O uso do vídeo como recurso pedagógico: conceitos, questões e possibilidades no contexto escolar. Trabalho de Conclusão de Curso. Universidade Estadual de Londrina, Londrina - Paraná.

.http://www.uel.br/ceca/pedagogia/pages/arquivos/2011\%20JOELMA\%20RIBEIRO\%20BETETTO.pdf.

Brasil. Ministério da Educação. (2018). Base Nacional Comum Curricular. Brasília.

http://basenacionalcomum.mec.gov.br/images/BNCC_EI_EF_110518_versaofinal_site.pdf

Chizzotti, A. (2003). Pesquisa em ciências humanas e sociais. Cortez.

Estadão. (2010, dezembro). Endividamento do brasileiro preocupa o ministério. Jornal Estadão. Acervo Digital. https://economia.estadao.com.br/noticias/geral,endividamento-do-brasileiro-preocupa-ministerio,45761e.

Ferreira, O. M. de C., \& Silva JR, P. D. da. (1975). Recursos audiovisuais para o ensino. (3. ed.). EPU.

Ferrés, J. (1996). Vídeo e Educação. 2. ed., Artes Médicas.

Gamboa, S. S. (2013). Projetos de pesquisa, fundamentos lógicos: a dialética entre perguntas e respostas. Argos.

Instituto Brasileiro de Geografia e Estatística. (2020). PNAD - Pesquisa Nacional por Amostra de Domicílio - Acesso à internet e à televisão e posse de telefone móvel celular para uso pessoal: 2018 / IBGE - Instituto Brasileiro de Geografia e Estatística. Coordenação de Trabalho e Rendimento. https://biblioteca.ibge.gov.br/index.php/biblioteca-catalogo?view=detalhes\&id=2101705.

Moran, J. M. (1994, maio/ago.). Influência dos meios de comunicação no conhecimento. Ciência da Informação, 23, 233 -238.

Moran, J. M. (1995). O vídeo na sala de aula. Revista Comunicação e Educação. ECA-Ed. Moderna, 1(2). 27-35. ISSN: 0104-6829.

http://www.revistas.univerciencia.org/index.php/comeduc/article/view/3927/3685

Moreira, M. A. (2006). A Teoria da aprendizagem significativa e sua implementação em sala de aula. UnB. 185 p.

Rosado, E. M. S. (1994). Vídeo e aquisição de conhecimento: alguns elementos de uma metodologia de pesquisa. Intercom - Revista Brasileira de Ciências da Comunicação. 17(2), 121-131. ISSN: 1980-3508. http://www.portcom.intercom.org.br/revistas/index.php/revistaintercom/article/view/855.

Sousa, E. R.(2017). As contribuições do ensino desenvolvimental de Davydov para o ensino de geometria euclidiana no curso de licenciatura em matemática. [Dissertação Mestrado em Educação para Ciências e Matemática, Instituto Federal de Goiás - IFG]. https://repositorio.ifg.edu.br/handle/prefix/424

Vaz, D. A. F., \& Sousa, E. R.(2020). Um experimento didático-formativo davydoviano sobre o Teorema de Pitágoras. In S. V. L. Rosa. (Org.) Formação de professores e ensino nas perspectivas Histórico-Cultural e Desenvolvimental: pesquisa e trabalho pedagógico. (215-228). Appris editora..

Vogel, M. J. (2015). O uso do vídeo em sala de aula: um novo sentido à aprendizagem a partir das tecnologias da informação e comunicação. III Congresso Internacional de Educação Científica e Tecnológica - CIECITEC. Universidade Regional Integrada, Santo Ângelo - RS.

http://www.santoangelo.uri.br/ciecitec/anaisciecitec/2015/resumos/comunicacao/833.doc. 